\title{
«UNA VIDA TODA DE FANTASÍAS»: EL ELEMENTO FANTÁSTICO EN EL TEATRO DE ALEJANDRO CASONA ${ }^{1}$
}

\author{
«UNA VIDA TODA DE FANTASÍAS»: FANTASTIC ELEMENTS IN THE \\ THEATRE OF ALEJANDRO CASONA
}

\author{
María ÁLVAREZ ÁLVAREZ \\ Universidad de Oviedo \\ alalvarezmaria@gmail.com
}

Resumen: El presente artículo pretende estudiar la presencia del elemento fantástico en el teatro de Alejandro Casona, uno de los rasgos fundamentales que la crítica ha señalado en su obra, en la que lo fantástico cobra vital importancia para el desarrollo de la acción y los planos real e irreal se funden y se nutren mutuamente, sin que uno pueda existir plenamente sin el otro. Por ello, también estudiaremos los procedimientos utilizados por el autor para configurar el elemento fantástico en sus obras y los objetivos perseguidos con ello. Nos centraremos en una selección de títulos: Otra vez el Diablo, La sirena varada, La dama del alba, La barca sin pescador, La casa de los siete balcones, Prohibido suicidarse en primavera y Los árboles mueren de pie.

Palabras clave: teatro del siglo XX; Alejandro Casona; teatro español contemporáneo; Generación del 27; literatura fantástica.

Abstract: This article aims to study the fantastic element woven in Alejandro Casona's plays as one of the main pillars of his work. As critics have pointed out, this fantastic element takes on vital importance in order to develop action both in real and unreal levels intertwining them thoroughly and making them impossible to unravel. Thus, we will study Casona's procedure and goals while shaping this fantastic element within his works, focusing on the following titles: Otra vez el Diablo, La sirena varada, La dama del alba, La barca sin pescador, La casa de los siete balcones, Prohibido suicidarse en primavera and Los árboles mueren de pie.

Keywords: 20th century theatre; Alejandro Casona; contemporary Spanish theatre; Generación del 27; fantastic literature.

\footnotetext{
${ }^{1}$ El presente trabajo se ha realizado gracias a una ayuda predoctoral del Programa «Severo Ochoa» para la formación investigadora y docente, subvencionado por el Gobierno del Principado de Asturias.
} 
asta hace relativamente poco tiempo, la literatura fantástica no contaba con el favor y la atención de la crítica académica, que la dejaba al margen de sus estudios y clasificaciones, considerándola un género o categoría literaria menor. Por fortuna, el panorama ha cambiado notablemente en los últimos años, lo que ha provocado que la modalidad fantástica haya conocido un extraordinario interés a través de numerosos análisis, acercamientos e intentos de definición, asunto, este último, de difícil concreción, como se verá más adelante. Como Roas (2017b: 9) ha apuntado recientemente, dentro del panorama cultural español en concreto, no ha sido hasta el siglo XXI cuando han comenzado a aparecer un buen número de estudios sobre lo fantástico en nuestro país, revalorizando con ello una categoría desdeñada hasta hace poco y contribuyendo al conocimiento y a la reconstrucción de la historia y evolución de lo fantástico español. A pesar de ello, la mayoría de los estudios publicados durante la segunda mitad del siglo XX y principios del XXI se han centrado en obras narrativas, siendo llamativo el abandono sufrido por el género dramático. Por suerte, en la última década se le ha ido concediendo mayor atención a este campo, que reclama así el espacio que efectivamente merece dentro de estos estudios.

La tesis doctoral de Matteo De Beni, publicada en 2012, abre en buena parte el camino, continuado por los monográficos de diversas revistas citadas en la bibliografía —Pygmalion y Brumal - o por la Historia de lo fantástico en la cultura española contemporánea dirigida por el mencionado Roas (2017a). De Beni (2012: 57) menciona la opinión de críticos (como Pavis, 2002) que negaban la posibilidad de que lo fantástico pueda expresarse en plenitud sobre la escena y relegaban esta modalidad al género narrativo. Así, el desinterés que la crítica había mostrado hasta entonces (también mencionado por Ambrosi, 2012: 9) podía hacer pensar en la inexistencia o marginalidad de lo fantástico en el teatro, pero como el propio De Beni demuestra ampliamente en su citado trabajo, el género dramático prueba ser un «sistema semiótico en el que lo fantástico puede sobresalir» (De Beni, 2012: 238), debido a la relevancia que la plasticidad o los elementos visuales (características esenciales del teatro) poseen en la literatura fantástica. De hecho, lo fantástico no ha dejado de manifestarse en la escena española del siglo XX, con numerosos y relevantes ejemplos. En buena parte, como López-Pellisa y De Beni (2014: 9) reflexionan, la vitalidad de la que goza esta modalidad en el teatro actual explicaría el creciente interés hacia ella desde la academia en los últimos años. El estudio de estas obras contribuye a acotar la definición de un concepto tan lábil como el de lo fantástico.

Para Roas (2017b: 10), este se caracteriza por presentar un «conflicto entre lo imposible y (nuestra idea de) lo real», de acuerdo con las leyes naturales del mundo que habitamos y que compartimos con los personajes de la obra, aspecto en el que vienen a coincidir (con más o menos matices) todos los intentos de definición. La vacilación o incertidumbre - la duda de Todorov (1981) - que provocaba tal conflicto era (y aún es, para muchos teóricos) el rasgo que fijaba 


\section{Tropelías. Revista de Teoría de la Literatura y Literatura Comparada, 32 (2019)}

«Una vida toda de fantasías»: el elemento fantástico en el teatro de Alejandro Casona

definitivamente la modalidad. Pero, como indica Cristini (2014: 34), la creciente atención a la manifestación de lo fantástico en el teatro de los últimos años ha provocado la aparición de nuevas cuestiones epistemológicas y, con ello, de nuevos intentos de definición.

Así, de nuevo Roas (2017b: 10-11) se decanta por centrarse en la inexplicabilidad del fenómeno presenciado $^{2}$, lo que involucra activamente al lector en la consideración de lo que es fantástico y lo que no, e insiste en advertir de la constante evolución de la definición del concepto. Orazi (2018) también distingue entre la perspectiva clásica de lo fantástico (que pone dos mundos paralelos e independientes, el real y el fantástico, en contacto a través de un acontecimiento anómalo) y lo neofantástico, que se daría en la literatura española a partir de los años 80 del último siglo. Este último consistiría en una evolución de la concepción y articulación literaria de lo fantástico:

[...] real y fantástico se perciben ahora como dos componentes de la vida cotidiana y ya no como dos mundos separados e independientes que de vez en cuando se rozan; lo que el texto neofantástico suele suscitar es desasosiego, desazón, inquietud y ya no (tan sólo) miedo o terror (Orazi, 2018: 108).

Ante todo esto, resulta evidente la dificultad que supone ofrecer una definición fija y cerrada de lo fantástico, caracterizado precisamente por su versatilidad y su vinculación con otras modalidades o categorías literarias, que puede observarse con el estudio de las obras. La misma Orazi (2018: 111) se lamenta de la dificultad de concretar una teoría de lo fantástico en la escena contemporánea debido a «la riqueza y profundidad de sus implicaciones formales y temáticas», y advierte además del riesgo que conllevaría simplificar en exceso su caracterización, por causa de la impresionante variedad de estructuras, mecanismos, figuras y rasgos que puede presentar. Así, Checa (2009), por ejemplo, repasa varias piezas de la primera mitad del siglo XX en las que lo fantástico se presenta íntimamente vinculado con la literatura utópica (o distópica) y de anticipación. Otros autores (como Pasqualicchio, 2012; Rubio Jiménez, 2012; De Beni y Martín Rodríguez, 2017) han señalado su relación con la poética simbolista, lo maravilloso, el surrealismo o lo grotesco, por no hablar de géneros teatrales como la comedia de magia, de santos o los autos sacramentales, en los que el factor espectacular o la intervención de personajes sobrenaturales o irreales los vincula a lo fantástico y los convierte en precedentes de lo que podríamos denominar teatro fantástico propiamente dicho.

De acuerdo con lo visto hasta el momento, lo que nos proponemos en el presente artículo es analizar la presencia de elementos que podríamos calificar como fantásticos en el teatro de Alejandro Casona (1903-1965). El autor asturiano es considerado uno de los máximos representantes y mayores innovadores del teatro de su generación, junto con García Lorca (Oliva, 2003). La crítica en conjunto ha destacado la importancia que lo fantástico (entendido en un sentido amplio) adquiere en su obra, hasta el punto de convertirse en uno de los rasgos esenciales de su producción: rara es la pieza en la que el elemento fantástico no aparece de una manera u otra. Debemos aclarar, eso sí, que cuando hablamos de lo fantástico casoniano no nos podemos ceñir a las definiciones clásicas del término, sino

\footnotetext{
${ }^{2}$ También para De Beni y Martín Rodríguez (2017: 99), por ejemplo, si el hecho inexplicable «permanece en la penumbra», sin aclaración racional, nos encontraremos entonces ante un hecho fantástico, caracterizado, por tanto, por provocar (en personajes y receptores de la obra) la incapacidad de decidir si lo ocurrido ha sido real o una alucinación.
} 
que su manifestación se acerca muy a menudo a otros terrenos, como el de lo maravilloso o sobrenatural. Manejamos, por tanto, una noción de lo fantástico como una «categoría amplia» (en palabras de Pasqualicchio, 2012: 22), de ahí que hablemos de elementos fantásticos en el teatro casoniano, y no de un teatro fantástico propiamente dicho. De hecho, si partimos de la intentio auctoris del propio Casona, él mismo no calificaba su obra con la etiqueta de «fantástica», a pesar de ser plenamente consciente de que estos elementos que podemos calificar como tales no pertenecen a la realidad tangible ni a lo racional. Como veremos a continuación, Alejandro Casona manejaba una particular concepción de la realidad y, precisamente por ello, su obra presenta interesantes rasgos sobre los que reflexionar en relación con la presencia de lo fantástico en escena, aunque no encaje totalmente con definiciones tradicionales y presente diversas peculiaridades que han de tenerse en cuenta.

Tenemos la suerte de contar con las palabras del propio autor reflexionando acerca del tono de su teatro, que definía como «la interferencia de realidad y fantasía, el mundo y el trasmundo, realidad objetiva y conciencia» (en Castellano, 1952: 393). Es conocida la polémica que surgió alrededor de su teatro, tras su regreso del exilio en los años 60, por parte de críticos y dramaturgos antifranquistas que le reprochaban la índole poética de su obra y la tildaban peyorativamente de «teatro de evasión», lo que se oponía al «realismo comprometido y responsable» (Aznar Soler, 2012: 369) que defendían estos dramaturgos ${ }^{3}$. El mismo Casona manifestó su desacuerdo con ello: «No soy un "escapista” que cierra los ojos a la realidad circundante, [...] Lo que ocurre es, sencillamente, que yo no considero sólo como "realidad" la angustia, la desesperación, la negación y el sexo. Creo que el sueño es otra realidad tan "real" como la vigilia» (en Cano, 1962). En efecto, en sus obras, el mundo real, tangible, cotidiano, se presenta ligado al mundo de lo irreal y de lo sobrenatural, cuya presencia se manifiesta con la total naturalidad que a esta segunda realidad le correspondía, según el propio Casona. Realidad y fantasía son, por tanto, la médula del teatro casoniano, dos aspectos que no son opuestos para nuestro autor, sino que se necesitan mutuamente, cosa que busca demostrar en sus piezas. De hecho, esta peculiar concepción de la realidad y su reflejo en su obra puede hacer pensar en la definición de «neofantástico» propuesta por Orazi y vista en páginas anteriores, según la cual lo real y lo fantástico son dos componentes de la vida cotidiana que, en ocasiones, se rozan, noción muy similar a la planteada por el propio dramaturgo en sus entrevistas. Quizás no sea muy descabellado, por tanto, ver en Casona un precedente de esta modalidad neofantástica que se desarrollará plenamente en las últimas décadas del siglo XX. Bien es cierto que, en el teatro casoniano, el efecto perturbador e inquietante o incluso el miedo que la presencia de lo fantástico pretendía suscitar está ausente. Lo que sí encontramos son reacciones de perplejidad o incredulidad en algunos personajes (y en el propio lector/espectador), incapaces de explicarse lo que está sucediendo ante sus ojos; en algunos casos, la explicación será proporcionada posteriormente, pero en otros permanecerá oculta.

\footnotetext{
${ }^{3}$ Aznar Soler (2012) estudia el caso concreto de las críticas hechas por Ricardo Doménech y las respuestas que estas recibieron desde filas partidarias del régimen y por parte del propio Casona, republicano exiliado en América entre 1937 y 1962.
} 
Hay que tener en cuenta, además, el peso de la tradición literaria y las tradiciones populares en la obra de Casona: la influencia de cuentos, leyendas y supersticiones se hace evidente en su tratamiento de temas y personajes vinculados al ámbito fantástico. La importancia de lo onírico manifestada por él mismo pone también en relación su obra con la estética surrealista, que algunos autores ya han señalado ${ }^{4}$. Lo fantástico, por tanto, se manifiesta en Casona mezclado con otras modalidades literarias y teatrales, siendo esto precisamente una de las principales características de lo fantástico en el teatro español contemporáneo, tal y como establece Matteo De Beni (2012: 237). Para comprender correctamente la concepción de lo fantástico en Casona, debemos tener en cuenta lo que el propio autor asturiano tenía por realidad, una realidad «caleidoscópica» (en palabras de Gurza, 1968) que supone la yuxtaposición de dos planos: el de la realidad y el de la irrealidad, el mundo externo y el interno. Lo que el propio escritor, glosando a Menéndez Pidal, explica así: «para los españoles, además de la realidad inmediata y vulgar, existe una segunda realidad contagiada de prodigio: una realidad "extraordinaria"» (en Cano, 1962)

Centrándonos ya en la producción casoniana, Rodríguez Richart (1963) realiza un intento de clasificación de la misma, en el que destaca veinte de sus obras como las más importantes del autor. Estas veinte son divididas en dos grupos, el primero de los cuales comprendería «sus obras más personales y características [...] las que mejor revelan el "sentido" de su teatro». Uno de los tres criterios que utiliza para realizar esta división es, precisamente, «el binomio que les sirve de base: mundo de la realidad - mundo de la fantasía» (39). A este primer grupo pertenecen las siete obras estudiadas en el presente trabajo, en el que, de acuerdo con lo expuesto hasta el momento, queremos mostrar cómo se manifiesta lo fantástico en el teatro de Casona, qué propósitos tiene en él y qué relación guardan entre sí estas siete obras. Por nuestra parte, hemos dividido estas piezas en dos grupos: en el primero, presenciamos la intervención de un ser sobrenatural en la trama: Otra vez el Diablo (1935), La dama del alba (1944) y La barca sin pescador (1945). En el segundo, se da una confrontación entre el mundo real y el irreal a través de unos personajes realistas: La sirena varada (1934), Prohibido suicidarse en primavera (1937) y Los árboles mueren de pie (1949). Aparte queda La casa de los siete balcones (1957), en la que encontramos elementos pertenecientes a ambos grupos.

Comencemos por el primer grupo mencionado. En estas obras, un ser sobrenatural se presenta en el mundo cotidiano de los personajes, normalmente para cumplir una función de gran importancia en el desarrollo de la trama. Estos seres son el diablo en Otra vez el Diablo y La barca sin pescador, la Muerte en La dama del alba y fantasmas en La casa de los siete balcones, todos ellos personajes recurrentes en los intentos de clasificación temática de la literatura fantástica (por ejemplo, Todorov, 1981:73-74); pero veamos las peculiaridades que presentan en el teatro de Casona.

\footnotetext{
${ }^{4}$ Medina Barrenechea (2015: 26-36), por ejemplo, repasa la presencia de las principales características del surrealismo literario en numerosas obras de Casona.

${ }^{5}$ Las palabras exactas de Menéndez Pidal (1949: XXXIX) son: «es propensión esencial de la imaginación española el tratar lo maravilloso, no como puramente fantástico, sino como una realidad extraordinaria, una segunda realidad».
} 
Otra vez el Diablo y La barca sin pescador comparten un tema típico: el pacto con el diablo ${ }^{6}$ La primera pieza es un «cuento de miedo en tres jornadas» (Casona, 1977d: 340) en el que el miedo está totalmente ausente: el subtítulo se trata de un guiño cómplice del autor hacia su público, basado en la abundante tradición popular de cuentos de miedo protagonizados por el demonio ${ }^{7}$. Pero este diablo no provoca temor alguno: muy al contrario, Casona crea un personaje cercano, amable e incluso simpático.

La primera vez que el Diablo aparece en escena, sale por detrás de un crucero que marca el cruce de dos caminos, lugar propicio para los pactos con el demonio según la tradición. Su entrada apenas tiene notas sobrenaturales:

\section{Por detrás de la cruz sale el Diablo, sin tramoya, con un misterio discreto. Anda sin hacer el menor ruido, dando en todo momento una sensación de ingravidez. Es un diablo maduro, sin edad. Viste pulcramente de riguroso luto: calzón, birrete y ferreruelo, y habla con una naturalidad mundana tocada a veces de melancolía (348).}

La humanización a la que Casona somete a su criatura tiene como resultado un diablo amable, educado, buen conversador, que se muestra molesto con el trato recibido por parte de los hombres: estos le culpan de todos los males, han sido injustos con él, lo han retratado feo y monstruoso y no han sabido agradecerle los favores que les ha hecho, pues, gracias a sus tentaciones, algunos de ellos llegaron a santos: «También los santos se han portado bastante mal conmigo. Y, sin embargo, si no hubiera sido yo, no hubieran sido ellos. ¡Lo que yo trabajé por su santidad...!» (350).

Se trata de un diablo que se gana el favor del público inmediatamente y que, harto de su mala fama, se propone hacer el bien, «pero un bien diabólico..., con intriga y tentación» (351). Su salida de escena resulta aún más natural de lo que había sido su entrada: «DiABLO.- (Repentinamente grave.) Buenas tardes. ( $Y$ se aleja mustio, silbando una cancioncilla y dando con el pie a la hojarasca del camino)» (352).

Su última aparición es, acaso, un poco más espectacular: en esta ocasión decide entrar por la chimenea y, cuando el Estudiante le señala que podría haber entrado más cómodamente por la puerta, el Diablo le responde: «Sin duda. Pero ¿qué quieres? Es una pequeña vanidad de Diablo» (380). Vemos que el sentido del humor, inteligente, elegante, irónico, es uno de los principales rasgos con los que Casona viste a este personaje, que lo acerca más al mundo de los humanos que al de lo sobrenatural. Así, lo vemos acercarse al fuego a calentarse, alegando que él está «acostumbrado a otro clima» (381) y goza al comprobar que el Hostelero, antiguo fraile, lo reconoce:

HOSTELERO.- Gracias, señor. (Le mira con inquietud y sale santiguándose disimuladamente.) DiABLO.- (Ríe.) Menos mal; todavía hay alguien que me recuerda (382).

\footnotetext{
${ }^{6}$ Robert Lima (1983) estudia el tratamiento por parte de Casona del tema del pacto con el diablo en estas dos piezas. Para el autor asturiano, el diablo es un viejo conocido: a él le dedica su memoria de licenciatura, en la que repasa la presencia y el valor del personaje en la literatura: declara que «Ni lo que es el Diablo como símbolo del Mal, ni lo que representa como antagonista de Dios» (Casona, 1974a: 1267) le interesa, sino como personaje literario.

${ }^{7}$ Precisamente por ello, quizás sea esta la obra de las estudiadas aquí que más se aleje de la etiqueta de lo fantástico y se acerque más al mundo de lo maravilloso, en el que se moverían todos los personajes de la pieza.
} 
Este diablo de 1935 guarda muchas similitudes con el que se nos presenta diez años después, en La barca sin pescador. De las obras estudiadas en este trabajo, es en esta donde, probablemente, encontramos mayor atención al empleo de los efectos espectaculares para lograr la representación de lo fantástico en escena. Además, el efecto de extrañeza o desconcierto que produce la irrupción de lo fantástico en el tejido de la realidad es aquí mucho más evidente que en otras piezas y, de hecho, el acontecimiento sobrenatural nunca queda satisfactoriamente explicado ${ }^{8}$.

Del mundo de cuento en un tiempo remoto de la anterior obra, pasamos ahora al mundo moderno: «Despacho del financiero Ricardo Jordán. Lujo frío. Sobre la mesa, "ticker” y teléfonos. En las paredes, mapas económicos con franjas de colores, banderitas agrupadas en los grandes mercados y cintas indicadoras de comunicaciones» (Casona, 1977a: 833).

El empresario, al borde de la bancarrota, abandonado por sus socios, traicionado por su amante, lleva noches sin dormir. Juan, su asistente, le lleva un cóctel para ayudarlo a descansar: «Como el señor lleva tres noches sin dormir, me he permitido... ¡Pruébelo y me lo agradecerá! Pero con cuidado. ¡Es una fórmula para soñar de pie!» (835). En estas circunstancias, Jordán queda solo en su despacho y Casona aprovecha los recursos escénicos a su alcance para transformar el espacio en un lugar propicio para la intromisión de lo sobrenatural:

Rumor de lluvia. Las luces bajan visiblemente mientras se oye un extraño fondo de música, obsesiva y monótona. La puerta corrediza del foro se abre sola, lentamente, sin ruido alguno, dando paso al Caballero de Negro. Vuelve a cerrarse a su espalda con un discreto misterio. (838)

El diablo vuelve a adaptarse al lugar y tiempo en los que transcurre la acción: viste traje de chaqueta, de riguroso luto, y carga con una cartera de negocios; «solamente su sonrisa fría, su nariz rapaz y su barbilla en punta denuncian, bajo la apariencia vulgar, su perdurable personalidad» (838). Esta vez, su aparición desconcierta a Jordán, que no se explica de dónde ha salido ni quién puede ser esa persona que le habla con tanta confianza, a pesar de que su cara le resulta familiar:

RICARDO.- Creo que he visto esa cara alguna vez... no sé dónde.

CABALLERO.- En un libro de estampas que tenía tu madre, donde se hablaba ingenuamente del cielo y del infierno. ¿Recuerdas? Página octava..., a la izquierda (838).

El tiempo se detiene y nadie responde a las llamadas de Ricardo. El diablo, de nuevo educado, elegante, se comporta como un hombre de negocios y, como tal, le propone un trato al empresario: lo salvará del desastre financiero a cambio de su «voluntad de matar» (842) a un hombre, a un completo desconocido de una remota aldea que el Caballero parece escoger al azar en un globo terráqueo. Casona logra transportarnos hasta ella sin necesidad de movernos del despacho de Jordán, gracias a un inteligente uso de la luz y del sonido: la primera va bajando gradualmente y centrándose en las figuras de Jordán y el Caballero. Por su parte, el sonido del viento, una canción lejana y la melodía de un acordeón van apoderándose de la escena, mientras el diablo narra la muerte de la víctima, un anónimo

\footnotetext{
${ }^{8}$ Todorov (1981: 18-24) señala que la «posibilidad de suministrar dos explicaciones del acontecimiento sobrenatural» (20), la ambigüedad o vacilación entre ilusión y realidad, que observamos en esta obra o en La casa de los siete balcones, es rasgo definidor de lo fantástico.
} 
pescador de la costa noruega. Todo culmina con Jordán, hipnotizado, firmando el contrato ofrecido y con el grito de la esposa del pescador, que nos devuelve bruscamente a la realidad del despacho. El uso de la gradación de los recursos escénicos es magistral: logra que el espectador se vaya adentrado paulatinamente en la escena y participe de la experiencia fantástica, y que la tensión vaya poco a poco aumentando hasta estallar con el grito de la mujer, que deja helado a Jordán (y a nosotros con él). Como apunta J. F. Toms (1961: 221), el uso del viento es particularmente efectivo «in creating an atmosphere of suspense and fear, because it symbolizes forces beyond the control of man, and therefore becomes synonymous with the supernatural». El poder de la representación teatral convierte al público en testigo directo del ambiente sobrenatural que el autor ha sabido crear.

Tras alcanzar su objetivo, el Caballero recoge sus cosas y se marcha tal y como había venido: «La puerta se abre silenciosamente y sola como cuando entró y se cierra de nuevo tras él. Vuelve la luz normal. Ricardo [...] reacciona, restregándose los ojos como si despertara. Mira el reloj. El péndulo vuelve a marchar» (Casona, 1977a: 845). El empresario intenta buscar una explicación racional a lo que ha sucedido y lo achaca a los nervios y al cansancio acumulado durante días. Pero el hallazgo de un guante negro sobre su mesa le hace dudar: ¿ha sido real o ha sido un sueño? La subversión momentánea de las leyes naturales (el tiempo detenido), la falta de testigos, el guante que puede o no pertenecer al misterioso visitante, el estado mental y físico en el que se encuentra Jordán... todo ello contribuye a fomentar la duda acerca de la realidad de lo apenas presenciado.

Un dilema similar nos lo propone La casa de los siete balcones, en la que Uriel, un chico de corta edad, incapaz de hablar desde su nacimiento, es víctima de la codicia de su padre. Aislado del mundo exterior, se comunica con los fantasmas de su madre, su abuelo y una amiga de la infancia. Casona los hace aparecer en escena y mantener conversaciones con Uriel con total naturalidad: la presencia de lo sobrenatural es señalada, de nuevo, por el cambio en la luz, que baja «tornándose vagamente irreal» (Casona, 1974b: 288) y con el sonido de un arpa. Estos encuentros entre Uriel y los fantasmas siempre se producen cuando aquel está solo y en un momento de crisis, lo que nos lleva, de nuevo, a dudar de la naturaleza de lo que presenciamos: ¿estas apariciones son reales, o son fruto de la imaginación de Uriel, funcionando como una especie de mecanismo de defensa? Merece la pena señalar que aquí la presencia de los personajes fantásticos no es inquietante ni perturbadora: muy al contrario, su aparición en escena es tranquilizadora y precisamente se produce cuando Uriel necesita protegerse de la hiriente realidad externa.

Avanzando en la obra del autor y ampliando su concepción de lo fantástico y su relación con la realidad cotidiana, nos encontramos con la tercera pieza de nuestro estudio, La dama del alba. Considerada la obra más perfecta de Casona en todos los sentidos (Ruiz Ramón, 1975: 239), en ella observamos una maravillosa conjunción de los planos real e irreal que tanto interesaba al autor. Esto lo consigue, principalmente, a través de tres procedimientos:

- el uso de un lenguaje altamente poético, sugerente, cargado de símbolos, metáforas y comparaciones; 


\title{
Tropelías. Revista de Teoría de la Literatura y Literatura Comparada, 32 (2019) «Una vida toda de fantasías»: el elemento fantástico en el teatro de Alejandro Casona
}

\author{
- la alusión constante a supersticiones y leyendas en el día a día de los personajes, en su \\ vida cotidiana; \\ - por supuesto, con la presencia de la Muerte, en el personaje de la Peregrina.
}

En cuanto al lenguaje, este contribuye a crear una atmósfera poderosamente sugestiva, aunque sin alejarse nunca del medio rural en el que se mueven los personajes. A este mundo pertenecen las leyendas y supersticiones que recoge la obra, que son presentadas con la mayor naturalidad. Adela Palacio, en su estudio, hace notar que en el mundo rural asturiano en el que creció Casona (al que dedica esta obra y en el que viven sus personajes), el mundo mitológico y las leyendas son «tan reales [...] como el cultivo del maíz o la recolección de las castañas. El campesino pasa del mundo de la imaginación al de la vida material con suma facilidad: para él todo es una sola realidad» (Palacio, 1963: 200) $)^{9}$.

En efecto, así nos lo presentan Telva (la criada), el Abuelo o los muchos jóvenes que se acercan a la casa de los protagonistas. Además, tengamos en cuenta que buena parte de la acción se desarrolla en la noche de San Juan, noche mágica por excelencia, y Casona no escoge este momento por casualidad $^{10}$.

La desaparición (que todos toman por muerte) cuatro años atrás de Angélica, la hija mayor de la familia protagonista, alimenta la leyenda del río de la aldea:

ABUELO.- Ya ha ocurrido lo mismo otras veces. El remanso no tiene fondo.

TELVA.- Dicen que dentro hay un pueblo entero, con su iglesia y todo. Algunas veces, la noche de San Juan, se han oído las campanas debajo del agua (Casona, 1996: 65-66).

La propia Peregrina, que aparece misteriosamente en la casa en mitad del primer acto, aprovechará esta historia al final de la obra: cuando comprende que Angélica sigue viva y que es a ella a quien ha venido a buscar, mezcla realidad y leyenda para crear una especie de cuento con el que explica a los niños lo que va a suceder esa noche, esto es, la aparición del cadáver de Angélica intacto, tanto tiempo después de su supuesta muerte:

PEREGRINA.- Una vez era un pueblo pequeño [...] Una aldea tranquila como un rebaño a la orilla de un río. [...] En el río había un remolino profundo [...] adonde no dejaban acercarse a los niños. Era el monstruo de la aldea. Y decían que en el fondo había otro pueblo sumergido, con su iglesia verde tupida de raíces y sus campanas milagrosas, que se oían a veces la noche de San Juan. [...] Un día la muchacha desapareció en el remanso. Se había ido a vivir a las casas profundas donde los peces golpeaban las ventanas como pájaros fríos; y fue inútil que el pueblo entero la llamara a gritos desde arriba. Estaba como dormida, en un sueño de niebla, paseando por los jardines de musgo sus cabellos flotantes y la ternura lenta de sus manos sin peso. Así pasaron los días y los años... [...] Y por fin el milagro se hizo. Una noche de hogueras y canciones, la bella durmiente del río fue encontrada, más hermosa que nunca. Respetada por el agua y los peces, tenía los

\footnotetext{
${ }^{9}$ Crecer en este medio rural explicaría en buena parte la peculiar concepción de la realidad defendida por Casona en su obra. Menéndez Pidal (1949: XXXVIII) notó cómo la literatura tradicional del noroccidente de la Península no se muestra tan refractaria a lo sobrenatural como la del resto del territorio: en sus narraciones «manejan aún restos de una mitología antigua, hadas, [...] nuberos, trasgos, seres olvidados casi totalmente en el resto de la Península».

${ }^{10}$ Newberry (1974) recoge en su estudio algunas de las supersticiones y tradiciones de esta noche, y el propio Casona incluye en esta pieza un buen número de las creencias populares asturianas.
} 
cabellos limpios, las manos tibias todavía, y en los labios una sonrisa de paz... como si los años del fondo hubieran sido sólo un instante (125).

La representación de la Muerte en esta obra ha llamado la atención de la crítica (véase, por ejemplo, Rodríguez Richart, 1996: 22-28). En ella, aparece representada como una peregrina que, como ella misma dice, no puede descansar ni detener su paso nunca. Es una mujer extremadamente hermosa, comparada varias veces con una reina de cuento por los niños, de «rostro hermoso y pálido», «sonrisa tranquila» (Casona, 1996: 69), las «manos blancas ${ }^{11}$ como una gran señora» (70) y una forma extraña de hablar. Hay algo misterioso en ella: lo perciben el perro de la casa (que ladra anunciando la presencia de lo sobrenatural), los niños, a su manera, y el Abuelo, que, debido a su avanzada edad, averigua la identidad de la Peregrina. Ante él se muestra tal como es: lamenta su destino y declara que desea amar y ser amada, pero no puede; cuando el Abuelo la llama «traidora y cruel» (87), ella se excusa, pues no es su deseo hacer daño, sino proporcionar paz a los que sufren ${ }^{12}$.

Vemos que estos seres sobrenaturales de Casona, tradicionalmente cargados de connotaciones negativas, parecen querer rebelarse contra su propia naturaleza: el diablo quiere hacer el bien, la Muerte desea amar y vivir.

La sirena varada, Prohibido suicidarse en primavera y Los árboles mueren de pie, por su parte, forman una especie de trilogía por su temática, por su estructura y por su planteamiento. Las tres repiten un esquema similar: nos encontramos con uno o varios personajes que rechazan la realidad externa, caracterizada por su extrema violencia o crueldad. Este rechazo lleva a los personajes a su aislamiento, en un intento de evasión de esa realidad mezquina y en busca de la felicidad. Pero tal felicidad no se conseguirá hasta su reinserción en la realidad externa, siempre mejorada tras el contacto con la realidad interna. Este esquema básico se desarrolla con matices en las tres obras citadas. En ellas, esta segunda realidad (que funciona como mecanismo de defensa) no se presenta de la mano de un ser sobrenatural, sino que son personajes realistas los que la introducen, bien de forma voluntaria, bien involuntariamente, llevados por su locura. Lo fantástico, por tanto, se aleja aquí lo más posible de concepciones tradicionales, acercándonos más en ocasiones al terreno de lo surrealista. Los personajes crean ese segundo mundo o realidad y, en algunas ocasiones, lo reclaman como una necesidad.

En La sirena varada encontramos los dos casos antes mencionados: en ella vemos cómo, a un «viejo caserón con vagos recuerdos de castillo y de convento» (Casona, 1977b: 293), llega don Florín con la intención de visitar a su viejo amigo Ricardo. Casona nos adentra en una atmósfera sugestiva,

\footnotetext{
${ }^{11}$ Ziomek (1970) estudia el simbolismo del color blanco en La dama del alba y su relación con la muerte y el más allá. La misma interpretación podemos hacer en La casa de los siete balcones, en la que los fantasmas, pálidos, aparecen totalmente vestidos de blanco. Por el contrario, el diablo, en las dos obras estudiadas, siempre viste de luto.

${ }^{12}$ La dama del alba ha sido puesta en relación con piezas fantástico-simbolistas, como La intrusa, de Maeterlink, o La dama del mar, de Ibsen, aunque es evidente que sus planteamientos y efectos no pueden distar más de los perseguidos por Casona en su obra.
} 
de nuevo a través del uso de las luces, «indirectas, verdes y rojas» (293), que sugieren un tono de irrealidad. Ricardo se ha instalado en la casa buscando huir de la realidad, harto de su mediocridad:

RICARDO.- [...] Encuentro que la vida es aburrida y estúpida por falta de imaginación. [...] Y he pensado que en cualquier rincón hay media docena de hombres interesantes, con fantasía y sin sentido, que se están pudriendo entre los demás. Pues bien: yo voy a reunirlos en mi casa, libres y disparatados. A inventar una vida nueva, a soñar imposibles. Y todos conmigo, en esta casa: un asilo para huérfanos de sentido común. (297)

Junto a él, se encuentra su inseparable mayordomo, Pedrote, Daniel, un pintor que se ha vendado los ojos para imaginar colores nuevos, y un fantasma, don Joaquín, en realidad antiguo ocupante de la casa abandonada que se ve obligado a cumplir este papel por miedo a quedarse sin un sitio donde vivir. Pronto está prevista la llegada a la casa de un payaso de circo «que conoce la Biblia y las estrellas [...] un hombre sin sentido, soñador y borracho [...] el presidente ideal» para esa «república» (300) donde no existe el sentido común. Pero en su lugar, a este mundo voluntariamente irreal llega Sirena, una mujer envuelta en misterio, que no se sabe de dónde viene ni quién puede ser realmente, que repite ser una sirena real y estar enamorada de Ricardo. De nuevo, Casona ha ido construyendo gradualmente este primer acto, aumentando poco a poco la presencia de lo fantástico hasta llegar al clímax, con la intervención cuasi sobrenatural de Sirena.

Si en este primer acto predomina de forma indiscutible la irrealidad, en el tercero y último lo hará la realidad. El segundo sirve de puente entre ellos: el primero finalizaba con la materialización de los sueños de Ricardo en el personaje de Sirena, pero el segundo terminará golpeándonos con la realidad: la muchacha está loca debido a los abusos recibidos de su antiguo jefe, y el descubrimiento de la verdad dará paso a un tercer acto en el que las luces evocadoras han desaparecido y la realidad se ha impuesto.

En Prohibido suicidarse en primavera, el autor nos introduce desde el comienzo en un medio peculiar, extravagante:

En el Hogar del Suicida, sanatorio de almas del doctor Ariel [...]. Todo aquí es extraño, sugeridor [...]: el mobiliario, la plástica, el trazado de las arquerías, la disposición indirecta de las luces acristaladas. En las paredes, bien visibles, óleos de suicidas famosos reproduciendo las escenas de su muerte: Sócrates, Cleopatra, Séneca, Larra. [...] sobre el dintel, una inscripción que dice: «Galería del Silencio». En frente, otra semejante, pero clara y sin puertas: «Jardín de la meditación» (Casona, 1977e: 475).

La decoración, los carteles, incluso el nombre de algunos personajes, nos transmiten la sensación de irrealidad: la Dama Triste o el Amante Imaginario, algunos de los suicidas en potencia, recorren la casa lamentándose de que sus fantasías no se corresponden con la realidad. La institución, supuestamente creada para facilitar la muerte a quienes la buscan, pretende en realidad salvarlos. El personaje de Alicia es el que más se acerca a acabar con su vida, movida por el hambre y la soledad, pero encontrar una forma de ser útil, como enfermera en el mismo sanatorio, le da motivos para vivir.

De forma similar, en el primer acto de Los árboles mueren de pie nos encontramos con un ambiente muy parecido: Casona sumerge al espectador en un escenario confuso, en el que es difícil 
explicarse qué se está presenciando. En un primer momento todo parece normal, pero, poco a poco, elementos y personajes extravagantes hacen pensar que no puede tratarse del mundo real:
A primera vista estamos en una gran oficina moderna, del más aséptico capitalismo funcional. [...] En contraste con el aspecto burocrático hay acá y allá un rastro sospechoso de fantasía: redes de pescadores, carátulas, un maniquí descabezado con manto [...] armas inútiles, mapas coloristas de países que no han existido nunca (Casona, 1977c: 965).

Los personajes aparecen y desaparecen y mantienen conversaciones absurdas. Todo está envuelto en un aire de misterio: algo fuera de lo normal está ocurriendo sin que nosotros lo sepamos, pero este toque de irrealidad está tratado con la mayor naturalidad, como si se tratase de cualquier trabajo rutinario de oficina. Compartimos nuestro desconcierto con dos de los protagonistas, Isabel y Balboa, que a mitad del primer acto se ven inmersos en este mundo de locos, incapaces de entender qué sucede. Al igual que en La sirena varada y Prohibido suicidarse en primavera, tras sumergir al espectador y a los personajes en este mundo al margen de la realidad, nos ofrecen la explicación: se trata de una especie de institución de caridad, una ONG extravagante que busca consolar a los tristes, dar esperanza a quienes la han perdido e introducir el misterio en la vida cotidiana.

La conversación entre Isabel y Mauricio (director de la casa) en este primer acto tiene especial relevancia, pues considero que aquí se encuentran expuestas algunas de las ideas más importantes del pensamiento de Casona: Mauricio confiesa que era él el supuesto fantasma que se había aparecido tiempo atrás en un barrio obrero, causando sensación en el vecindario. Para Mauricio, como para Casona, esa intromisión de lo fantástico en la vida cotidiana resulta fundamental: «sembrar una inquietud o una ilusión» es «labor tan digna [...] como sembrar trigo» (986): si el último alimenta el cuerpo, la ilusión alimenta el alma.

Poco después, Alicia, sin dar crédito, pregunta:

ALICIA. - ¿De verdad, de verdad, no están ustedes un poco...?

MAURICIO (ríe).- Dígalo, dígalo sin miedo; tal como va el mundo, todos los que no somos imbéciles necesitamos estar un poco locos» (988-989).

Casona defiende la necesidad de la locura, de la fantasía, para poder salvarse de los aspectos más crueles de la realidad: la soledad, el hambre, la codicia, el egoísmo, la violencia... incluso la rutina o la mediocridad.

Volviendo a La casa de los siete balcones, la tía de Uriel, Genoveva, una solterona que a pesar de sus años sigue esperando la vuelta de su prometido de América, representa también el contacto con esta segunda realidad. Por un lado, de forma voluntaria, evita tratar de todo lo que no le gusta «tachándolo», en especial a su violento cuñado y a la amante de este:

GenoveVA. $-[\ldots]$ Deja de trabajar y tacha el viernes.

RosinA.- ¿Tacharlo? ¿Cómo?

GenoveVA.- Como yo. Todo lo feo, lo sucio, lo grosero, se tacha y en paz. ¿Ves las palabras brutas del señor cuando me insulta? Tachados los insultos. ¿Ves que las comadres se guiñan el ojo cuando yo paso? Tachados los ojos (Casona, 1974b: 261). 
Esta negación voluntaria de la realidad está acompañada por otra de tipo involuntario: Genoveva ha perdido la razón, la noción de lo que es real y lo que no: piensa que ha ido a misa de domingo cuando es viernes, que ha paseado por el puerto cuando vive tierra adentro... Genoveva vive entre dos mundos, entre dos realidades, pero no sabe distinguir cuál es cuál, de ahí su tragedia.

\section{Conclusiones}

En el teatro de Alejandro Casona, la realidad cotidiana se ve invadida por la presencia de elementos que no pertenecen naturalmente a ella. Bien a través de la intervención de personajes sobrenaturales, bien siendo introducidos (voluntariamente o no) por personajes realistas, bien gracias al poder evocador y sugerente de la palabra poética, el mundo en el que viven sus personajes se mueve entre dos realidades, la cotidiana y la fantástica, entendiendo esta última en su acepción más amplia: en contacto con lo maravilloso, lo legendario, lo popular o lo surrealista, los elementos fantásticos que hallamos en sus piezas se reinventan y recrean de acuerdo con la especial concepción de la realidad que manejaba el autor y el propósito que este buscaba con su inclusión en sus obras.

Para conseguir su representación en escena, el empleo de los recursos escénicos y espectaculares (luz, música, sonido, tramoya, maquillaje, etc.) resulta esencial; a través de ellos, el espectador pasa a ser testigo directo de los acontecimientos sobrenaturales: la representación teatral enriquece la experiencia del receptor ante la presencia de lo fantástico, que vive en primera persona. Otro rasgo particular de estas obras es la extraordinaria naturalidad con la que, por lo general, el elemento fantástico está introducido y tratado en ellas, así como la humanización y la cercanía de sus personajes sobrenaturales, tan similares a los seres humanos.

Pero quizás lo más importante a la hora de estudiar los elementos fantásticos en el teatro de Casona sea la función que estos cumplen en él: su presencia en la realidad cotidiana es necesaria para alcanzar la estabilidad. Sin ello, sin ese mundo irreal (para él, tan real como lo tangible), la felicidad no es posible, como tampoco es posible alcanzarla recluyéndose en el mundo interior, que no deja de ser una mentira que acaba estallando. Es imposible vivir «una vida toda de fantasías», como le recrimina don Florín a Ricardo en La sirena varada (Casona, 1977b: 298), pero es necesario ese «ramalazo de misterio» que reclama Mauricio en Los árboles mueren de pie (Casona, 1977c: 986). El teatro de Casona demanda la necesidad de encontrar el equilibrio, de armonizar ambos planos, ambos mundos para él tan importantes.

\section{Referencias bibliográficas}

Ambrosi, P. (2012): «Introducción: para un acercamiento a lo fantástico teatral», en Modalidades de lo fantástico teatral, monográfico de Pygmalion, núm.4, pp. 9-12.

AZNAR SOLER, M. (2012): «Ricardo Doménech y el teatro de Alejandro Casona: breve historia de una polémica», en Escena y literatura dramática en el exilio republicano de 1939: Drama/Theatre, monográfico de Anales de la Literatura Española Contemporánea, vol. 37, núm. 2, pp. 367-396. 
CANO, J. L. (1962): «Charla con Alejandro Casona», Ínsula Revista de letras y ciencias humanas, núm. 191, p. 5.

Casona, A. (1974a): «El Diablo. Su valor literario, principalmente en España», en Obras completas, II. Madrid, Aguilar, pp. 1265-1368.

(1974b): La casa de los siete balcones, en Obras completas, II. Madrid, Aguilar, pp. 249-324. (1977a): La barca sin pescador, en Obras completas, I. Madrid, Aguilar, pp. 829-886.

(1977b): La sirena varada, en Obras completas, I. Madrid, Aguilar, pp. 289-339.

(1977c): Los árboles mueren de pie, en Obras completas, I. Madrid, Aguilar, pp. 963-1043.

(1977d): Otra vez el Diablo, en Obras completas, I. Madrid, Aguilar, pp. 341-393

(1977e): Prohibido suicidarse en primavera, en Obras completas, I. Madrid, Aguilar, pp. 473537.

(1996): La dama del alba. Madrid, Cátedra.

Castellano, J. R. (1952): «Casona y Asturias», Hispania, vol. 35, núm. 4, pp. 392-394.

CHECA, J. (2009): «Lo fantástico y el teatro español del siglo XX», en T. LÓPEZ-PELlisA y F. Á. MORENO SERRANO, eds., Ensayos sobre ciencia ficción y literatura fantástica: actas del Primer Congreso Internacional de literatura fantástica y ciencia ficción. Madrid, Asociación Cultural Xatafi, Universidad Carlos III de Madrid, pp. 152-177. Recuperado de https://e-archivo.uc3m.es/ handle/10016/8586\#preview

CRISTINI, M. (2014): «Performare il perturbante. Una proposta di definizione del fantastico teatrale contemporaneo a partire dall'unheimlich di Freud», en Teatro fantástico (siglos XX y XXI), monográfico de Brumal. Revista de Investigación sobre lo Fantástico, vol. 2, núm. 2, pp. 33-63.

De BenI, M. (2012): Lo fantástico en escena. Formas de lo imposible en el teatro español contemporáneo. Pontevedra, Academia del Hispanismo.

De Beni, M. y MARTín RodríGueZ, M. (2017): «Teatro 1900-1960», en D. RoAS, dir., Historia de lo fantástico en la cultura española contemporánea (1900-2015. Madrid/Frankfurt, Iberoamericana/Vervuert, pp. 99-120.

GuRZA, E. (1968): La realidad caleidoscópica de Alejandro Casona. Oviedo, IDEA.

LIMA, R. (1983): «El demonio en la sangre: génesis y superación del pacto diabólico en dos obras dramáticas de Alejandro Casona», Romance Notes, vol. 24, núm. 1, pp. 10-16.

LÓPEZ-PELlisA, T. y DE BENI, M. (2014): «Presentación», en Teatro fantástico (siglos XX y XXI), monográfico de Brumal. Revista de Investigación sobre lo Fantástico, vol. 2, núm. 2, pp. 7-10.

Medina BARRENECHEA, S. (2015): Una aproximación a El misterio del María Celeste de Alejandro Casona desde la perspectiva de la antropología simbólica. Tesis doctoral defendida en la Universidad de Málaga bajo la dirección de Adela Martínez García. Recuperado de https://riuma.uma.es/xmlui/bitstream/handle/10630/13089/TD_MEDINA_BARRENECHEA_S usana.pdf?sequence $=1$ 
MENÉNDEZ PIDAL, R. (1949): «Introducción. Caracteres primordiales de la literatura española», en G. DíAZ-PlAJA, dir., Historia general de las literaturas hispánicas, I. Barcelona, Barna, pp. XIIILIX.

Newberry, W. (1974): «Three Examples of the Midnight Summer Theme in Gloria, La dama del alba, and El curandero de su honra». Kentucky Romance Quarterly, vol. XXI, núm. 2, pp. 239259.

Oliva, C. (2003, 20 de marzo): «Alejandro Casona. Cien años de teatro moral», El Cultural. Recuperado de http://www.elcultural.com/revista/teatro/Alejandro-Casona/6674

ORAZI, V. (2018): «Sobre lo (neo)fantástico en la dramaturgia española contemporánea», Rivista di Filologia e Letterature Ispaniche, núm. 21, pp. 107-124.

Palacio, A. (1963): «Presencia de Asturias en la obra de Alejandro Casona», Boletín del Instituto de Estudios Asturianos, núm. XLVIII, pp. 155-201.

PASQUALICCHIO, N. (2012): «Prolegómenos a una investigación sobre teatro fantástico», en Modalidades de lo fantástico teatral, monográfico de Pygmalion, núm. 4, pp. 13-36.

PAVIS, P. (2002): Diccionario del teatro. Barcelona, Paidós.

ROAS, D., dir. (2017a): Historia de lo fantástico en la cultura española contemporánea (1900-2015). Madrid/Frankfurt, Iberoamericana/Vervuert.

- (2017b): «Prólogo», en D. RoAS, dir., Historia de lo fantástico en la cultura española contemporánea (1900-2015). Madrid/Frankfurt, Iberoamericana/Vervuert, pp. 9-14.

RodríGuez Richart, J. (1963): Vida y teatro de Alejandro Casona. Oviedo, IDEA. (1996): «Introducción», en A. CASONA, La dama del alba. Madrid: Cátedra, pp. 13-56.

RUBio JiMÉNEZ, J. (2012): «Elementos fantásticos en las Comedias Bárbaras, de Valle-Inclán», en Modalidades de lo fantástico teatral, monográfico de Pygmalion, núm. 4, pp. 73-92.

RuIz RAmón, F. (1975): Historia del teatro español. Siglo XX. Madrid, Cátedra.

TODOROv, T. (1981): Introducción a la literatura fantástica. México, Premia.

Toms, J. F. (1961): «The reality-fantasy technique of Alejandro Casona», Hispania, vol. 44, núm. 2, pp. 218-221.

ZIOMEK, H. (1970): «El simbolismo del blanco en La casa de Bernarda Alba y La dama del alba», Symposium, vol. 24, núm. 1, pp. 81-85. 